\title{
What can we learn from cost-of-illness studies?
}

\author{
Andreas Laupacis MD MSc FRCPC
}

$\mathrm{C}$ romay and Marshall (pages 677-682) have determined that the hospital cost of an acute lower gastrointestinal hemorrhage (LGIH), which is severe enough to require hospitalization in Ontario, is approximately $\$ 5,000$. The cost is higher in older patients and those with coronary artery disease than in the general population, and in patients treated in academic hospitals compared with patients treated in community hospitals.

Is this knowledge of importance? My answer would be, "a little, but not a lot". I can think of two main reasons for doing a study such as this: to estimate the cost of an illness to assist in health policy decisions, and to serve as an input into economic evaluations. Let us consider each of these.

\section{COST-OF-ILLNESS STUDIES}

Cost-of-illness studies are relatively common, but, in my opinion, not very useful. Proponents claim that they provide an estimate of the magnitude of a health problem (eg, diabetes mellitus costs US\$229 billion annually [1992 dollars]) (1) that can help decision makers determine where to allocate scarce health care resources. The problems are that there are simpler methods of looking at disease burden, cost-of-illness studies can be methodologically tricky, they say nothing about whether resources are being spent efficiently, and they provide no information about whether investing more resources on a particular disorder will improve the situation (2).

Knowing that the annual incidence of hospitalization for LGIH is about 25/100,000, combined with the clinical gestalt that most patients with an LGIH stay in hospital for a few days, do not visit the intensive care unit or need surgery, and survive the hospitalization period (they may be shaken, but are otherwise well), is probably all one needs to know to conclude that LGIH is a measurable societal health problem, but not nearly as important as many other health problems, such as coronary artery disease, breast cancer, depression or diabetes. Knowing the additional information that an average admission costs $\$ 5,000$ does not really add much.

Comay and Marshall confined themselves to assessing direct hospital costs, which they did a good job of measuring because they had access to a sophisticated costing system, and they measured actual resource use by using chart reviews. However, their title ("Resource utilization for acute lower gastrointestinal hemorrhage: The Ontario GI bleed study") is slightly misleading because there are many other resources to consider if one wishes to comprehensively evaluate the resource utilization of $\mathrm{LGIH}$, such as physician fees, patients' time lost from work during and after hospitalization, outpatient health care resources, out-of-pocket costs to visitors and care givers, etc. Although it is unlikely that inclusion of these costs would markedly affect the total cost in this instance, they can markedly change the results in other cost-of-illness studies, especially studies in chronic disorders such as multiple sclerosis, where patients can live for a long time with considerable disability. It is worth noting that most health economists feel that costing studies should not attempt to value time lost from work because, from the point of view of a society with less than 100\% employment, one person's loss of employment is another's gain, and the suffering associated with the illness can be measured using a quality-of-life instrument. Even if one wishes to attach a dollar value to the loss of work, the methodology to do so is not universally agreed on (3). Suffice it to say that deciding which costs to include in a cost-of-illness study, or the methods of measuring them, is often not straightforward.

Cost-of-illness studies sometimes seem to be commissioned by advocacy groups (patients, clinicians, pharmaceutical companies and others) because they want to stress the importance of their disease of interest. Although there is nothing wrong with this, it can sometimes lead to the unfortunate impression that one disease group is trying to outdo the other ("heart disease is actually a bigger problem for women than breast cancer") and can lead to apparent attempts to inflate the costs associated with a particular disease. One review of published American cost-of-illness studies found a sevenfold difference in the estimated cost of Alzheimer's disease among studies, and the total expenditures for the 80 diagnoses evaluated in American cost-of-illness studies (which evaluated a minority of diseases) was 2.1-fold greater than the actual expenditures for all of medical care (1)! We should also remember that relatively rare diseases are very important to those who suffer from them. Better methods of treatment should be aggressively pursued 
even if these diseases do not make the 'top 20' list of most costly illnesses.

The fact that a disease costs society a large amount of money says nothing about whether those funds are being wisely used, nor about the cost effectiveness of investing more resources into the prevention or treatment of that disease. To comment on the latter, one would need to conduct a full economic evaluation, which is the other use of costof-illness studies.

\section{COST-OF-ILLNESS STUDIES AS INPUTS INTO ECONOMIC EVALUATIONS}

It is important to remember that 'cost effectiveness', 'cost utility' and 'cost benefit' (terms used for different types of economic evaluations) all consist of two words. An economic evaluation considers both costs and effects (the difference between the three types of economic evaluations is in how the effects are measured) (4-6). Because the study by Comay and Marshall focuses only on costs and does not consider outcomes, it is not an economic evaluation, and, therefore, is of no help when trying to most efficiently allocate scarce health care resources (nor do the authors claim it is). However, the results of the study can be used as an input into an economic evaluation. For example, if one wished to compare the cost effectiveness of acetylsalicylic acid with that of warfarin for the prevention of stroke in patients with atrial fibrillation, one of the factors that would need to be considered is the difference in bleeding between the two antithrombotic agents. Some of that bleeding will be in the form of LGIH, and the cost calculated in the study by Comay and Marshall could be used to estimate the resources consumed by LGIH.

One of my professors once told me that economists are no more interested in dollars than clinicians are interested in mercury when they measure blood pressure. Both dollars and mercury are used as surrogates for the real outcome of interest. Dollars (or other currencies) are used to measure resources consumed. Resource consumption can vary markedly from jurisdiction to jurisdiction depending not only on the difference in how resources are valued (eg, higher fees for the same physician services in Ontario than in Quebec), but also on differences in clinical practice between regions (7). Thus, when trying to decide whether the results of an economic evaluation are applicable to your region, you must decide how similar the patterns of practice described in the study are to yours. For the Comay and Marshall study, two questions would be, "Are we more or less likely to admit patients with LGIH than the clinicians in this study?" and "Is the care of admitted patients similar?". Comay and Marshall present the reader with a description of the average amount of resources used by their patients (Table 2 [page 680]), which is very useful when trying to determine the generalizability of the results to different settings.

\section{SUMMARY}

Comay and Marshall did a good job of answering a very limited question: What is the cost to Ontario hospitals of patients admitted with LGIH? Not surprisingly, the study provides valid but limited answers. The results of the study can be used as an input into future economic evaluation, but on their own provide no useful information about future resource allocation to prevent or treat LGIH.

\section{REFERENCES}

1. Bloom BS, Bruno DJ, Maman DY, Jayadevappa R. Usefuless of US cost-of-illness studies in healthcare decision making. PharmacoEconomics 2001;19:207-13.

2. Drummond M. Cost-of-illness studies. A major headache? PharmacoEconomics 1992;2:1-4.

3. Koopmanschap MA, Rutten FFH. Indirect costs in economic studies. Confronting the confusion. PharmacoEconomics 1993;4:446-54.

4. Russell LB, Gold MR, Siegel JE, Daniels N, Weinstein MC, for the Panel on Cost-Effectiveness in Health and Medicine. The role of costeffectiveness analysis in health and medicine. JAMA 1996;276:1172-7.

5. Weinstein MC, Siegel JE, Gold MR, Kamlet MS, Russell LB, for the Panel on Cost-Effectiveness in Health and Medicine. Recommendations of the panel on cost-effectiveness in health and medicine. JAMA 1996;276:1253-8.

6. Siegel JE, Weinstein MC, Russell LB, Gold MR, for the Panel on Cost-Effectiveness in Health and Medicine. Recommendations for reporting cost-effectiveness analyses. JAMA 1996;276:1339-41.

7. Presentation and use of economic evaluation results. In: Drummond M, O'Brien B, Stoddart G, Torrance GW, eds. Methods for the Economic Evaluation of Health Care Programmes. Oxford: Oxford University Press, 1997:265-92. 


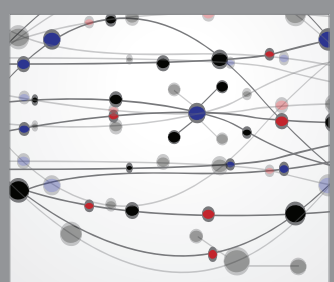

The Scientific World Journal
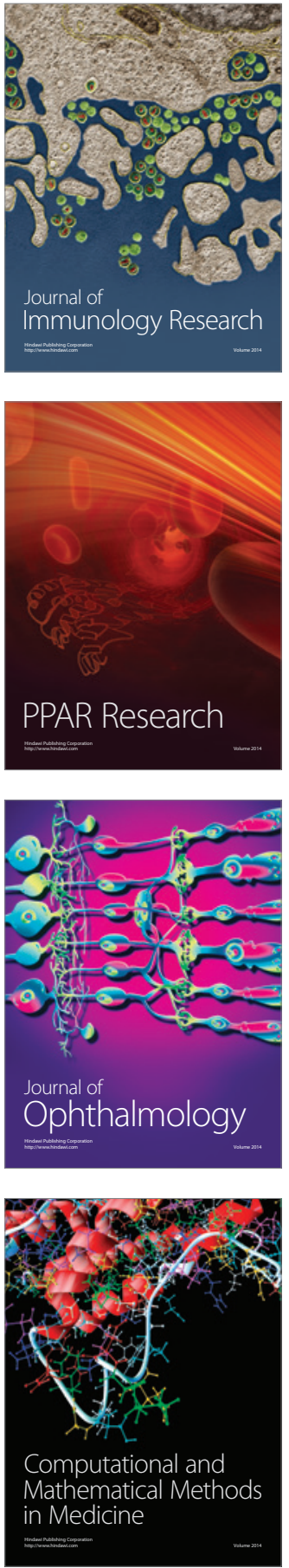

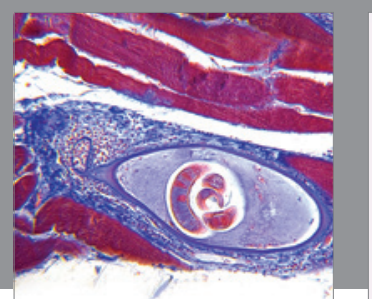

Gastroenterology Research and Practice

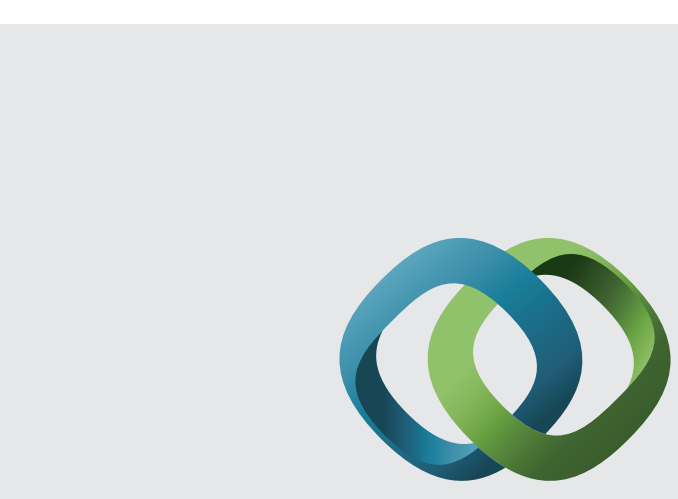

\section{Hindawi}

Submit your manuscripts at

http://www.hindawi.com
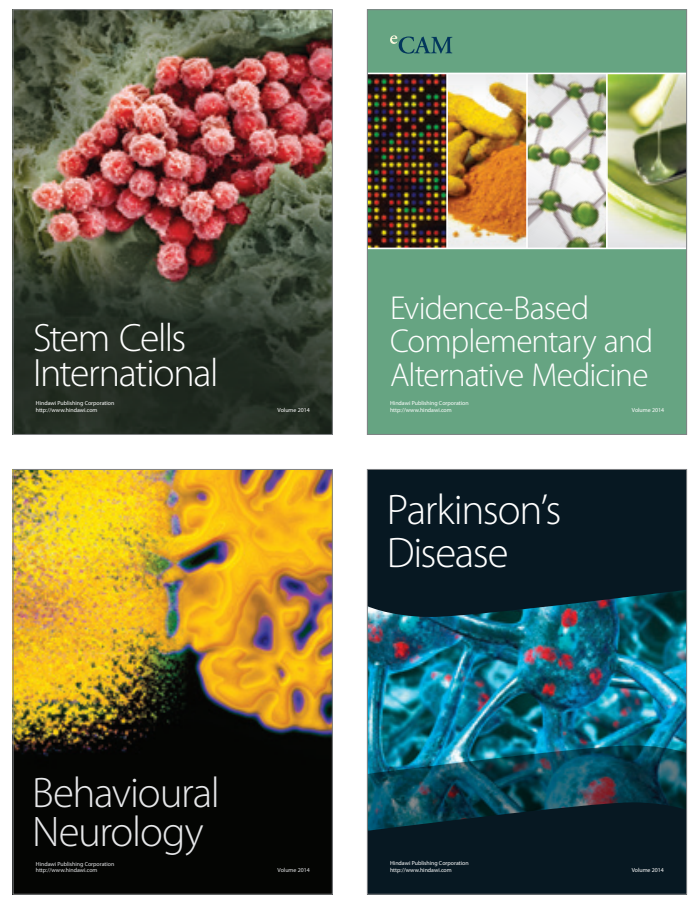
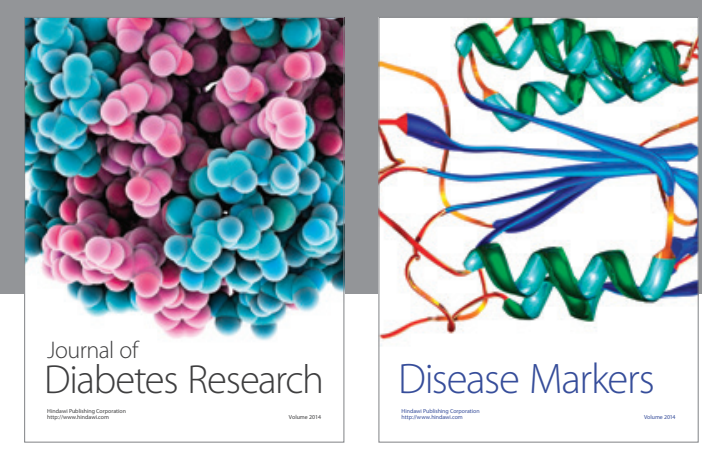

Disease Markers
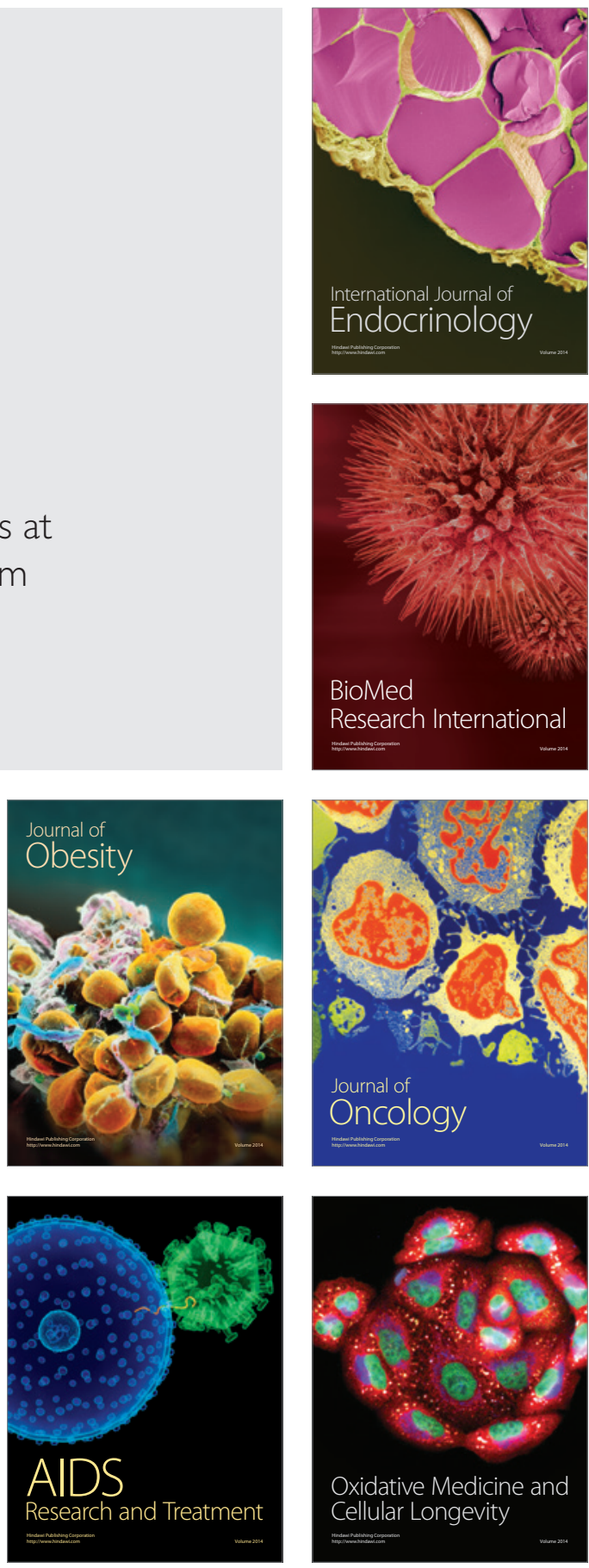